\title{
CONSTRUCTOS TEÓRICOS PARA LA GESTIÓN DE OPERACIONES DEL SISTEMA INTEGRADO DE VALOR Y DE SUMINISTRO DE EDUCACIÓN SUPERIOR (SIVSES)
}

\author{
César H. Ortega J. Universidad Nacional Autónoma de Honduras, \\ Facultad de Ciencias Económicas, \\ Instituto de Investigaciones Económicas y Sociales (UNAH-FCE-IIES), \\ Ciudad Universitaria, Edifício C2, Primer piso, Tel/Fax: 504-2239 1849 \\ E-mail: cortega@iies-unah.org
}

Ignacio Eguía Salina, Universidad de Sevilla, Organización Industrial y Gestión de empresas I, Tecnologías de la Información e Ingeniería de Organización, Tel: 95.448 .72 .00

E-mail: ies@us.es

Jorge A. Arita León. Universidad Nacional Autónoma de Honduras, Postgrado de la Facultad de Ciencias Económicas (POSFACE) Ciudad Universitaria, Edifício C1, Segundo piso, Tel/Fax: 504-2239 9046

E-mail: jarita.posface@gmail.com

\section{RESUMEN}

La presente investigación considera los fundamentos teóricos establecidos en la literatura por el modelo del Sistema Integrado de Valor y de Suministro de Educación Superior (SIVSES). Dicho modelo propone articular y balancear la demanda y la oferta de Educación Superior (ES), por medio de la integración total entre la cadena de valor de la vinculación de ES-demanda de ES, que permita medir el valor percibido por los demandantes de los profesionales de ES y de resultados de investigación de ES, y el valor añadido en sus insumos (ej. estudiantes y propuestas de investigación), durante los procesos de ambas cadenas de suministro de ES (docencia e investigación). Así pues, tomando el modelo teórico del SIVSES (como un mejor y más completo marco de referencia que modelos anteriores en la literatura), se plantean algunos elementos para su gestión de operaciones. Por tanto, este estudio exploratorio provee un marco conceptual importante para operativizar la teoría holística del SIVSES, su provisión de insumos, su oferta y su demanda, como paso previo al estudio empírico posterior que permita testear la teoría de tal modelo.

Palabras clave: Gestión de operaciones, Educación Superior (ES), Cadena de Suministro, Cadena de Valor, Demanda, Oferta, Vinculación con la Sociedad. 


\title{
The Theoretical Constructs for the Operations Management of the Higher Education Value and Supply Integrated System (HEVSIS)
}

César H. Ortega J. Universidad Nacional Autónoma de Honduras, Facultad de Ciencias Económicas, Instituto de Investigaciones Económicas y Sociales (UNAH-FCE-IIES), Ciudad Universitaria, Edifício C2, Primer piso, Tel/Fax: 504-2239 1849

E-mail: cortega@iies-unah.org

Ignacio Eguía Salina, Universidad de Sevilla, Organización Industrial y Gestión de empresas I, Tecnologías de la Información e Ingeniería de Organización, Tel: 95.448.72.00

E-mail: ies@us.es

Jorge A. Arita León. Universidad Nacional Autónoma de Honduras, Postgrado de la Facultad de Ciencias Económicas (POSFACE) Ciudad Universitaria, Edifício C1, Segundo piso, Tel/Fax: 504-2239 9046

E-mail: jarita.posface@gmail.com

\begin{abstract}
The present research takes on the theoretical fundaments, established in the literature by the model of Higher Education Value and Supply Integrated System (HEVSIS). The model proposes the articulation and balance of the Higher Education (HE) supply and demand, by mean of the total integration among the value chain of HE-demand link, which allows to measure the perceived value by demander of HE professionals and research results, and the added value on its inputs (e.g. students and research proposals), during processes of both HE supply chains (teaching and research). Hence, taking the theoretical model of HEVSIS (as a better and more complete reference framework than previous models in the literature), this study proposes some elements for its operations management. Therefore, this exploratory research provides an important conceptual outline to operationalize the HEVSIS holistic theory, HE input provision, and HE supply and demand requirements, as a previous step for the subsequent empirical research that allows testing the theory of such model.
\end{abstract}

Keywords: Operations management, Higher Education (HE), Supply chain, Value chain, Demand, Supply, Connection with Society. 


\section{INTRODUCCIÓN}

Una cadena de valor eficaz debe generar beneficios, por lo que su enfoque debe ser los beneficios acumulados a los demandantes, los procesos interdependientes que generan valor, y la demanda resultante con sus flujos de fondos, de información y de peticiones/solicitudes de productos o resultados que se pueden crear (Feller et al., 2006).

Por su lado, una cadena de suministro eficiente debe buscar la reducción de costos, en su esfuerzo de suministrar y entregar profesionales competentes y por, otro lado, resultados de investigación de calidad, valorados por el demandante, desde su inicio con el proveedor de insumos hasta el beneficiario/demandante final (ej. empleador y sociedad). Por tanto, el enfoque principal de la cadena de suministro debe ser la gestión de gastos y eficiencia de la oferta (ej. reducción de duplicidades, de no calidad, etc.), la gestión de información, y el flujo de insumos y materias primas de sus varias fuentes (proveedores) hasta los destinos (demandantes) finales como resultados finales (Habib, 2010).

Tomando Ramsay (2005), se puede decir que ambos tipos de cadenas (suministro y de valor) son perspectivas complementarias, de una Educación Superior (ES) extendida. Es extendida porque en la dirección de oferta (cadenas de suministro de docencia y de investigación) tiene procesos integrados que permiten flujos de información y flujos de estudiantes/profesionales e investigaciones, y en la dirección de demanda (cadena de valor de la vinculación de ES-demanda de ES) pueden existir flujos de información, flujos de valores de los demandantes y flujos de fondos. Además, ambos tipos de cadenas cubren la misma red de ES, con unidades e instituciones que interactúan para proveer profesionales y resultados de investigación de ES.

Sin embargo, como se ve en la Figura 1, la cadena de valor tiene al beneficiario/ demandante/usuario de ES como la fuente de valor, que significa un flujo de información del valor percibido, en forma de demanda, desde el demandante (final e 
intermedio), hasta el ofertante (ES), que incluye a su proveedor de insumos. Dicho flujo de demanda o cadena de demanda se manifiesta por el flujo de peticiones de graduados/profesionales y resultados de, investigaciones, y dinero paralelo al flujo de valor, fluyendo hacia atrás (es decir en dirección opuesta del flujo de oferta). Las cadenas de suministro (docencia e investigación), contrario a la de valor, son flujos hacia adelante, en forma de oferta, desde la entrada de estudiantes y propuestas/ anteproyectos de (líneas) de investigación, como los insumos provistos a la fuente de oferta (ES), siguiendo con el proceso de valor agregado de la ES, hasta el demandante/ beneficiario (intermedio y final).

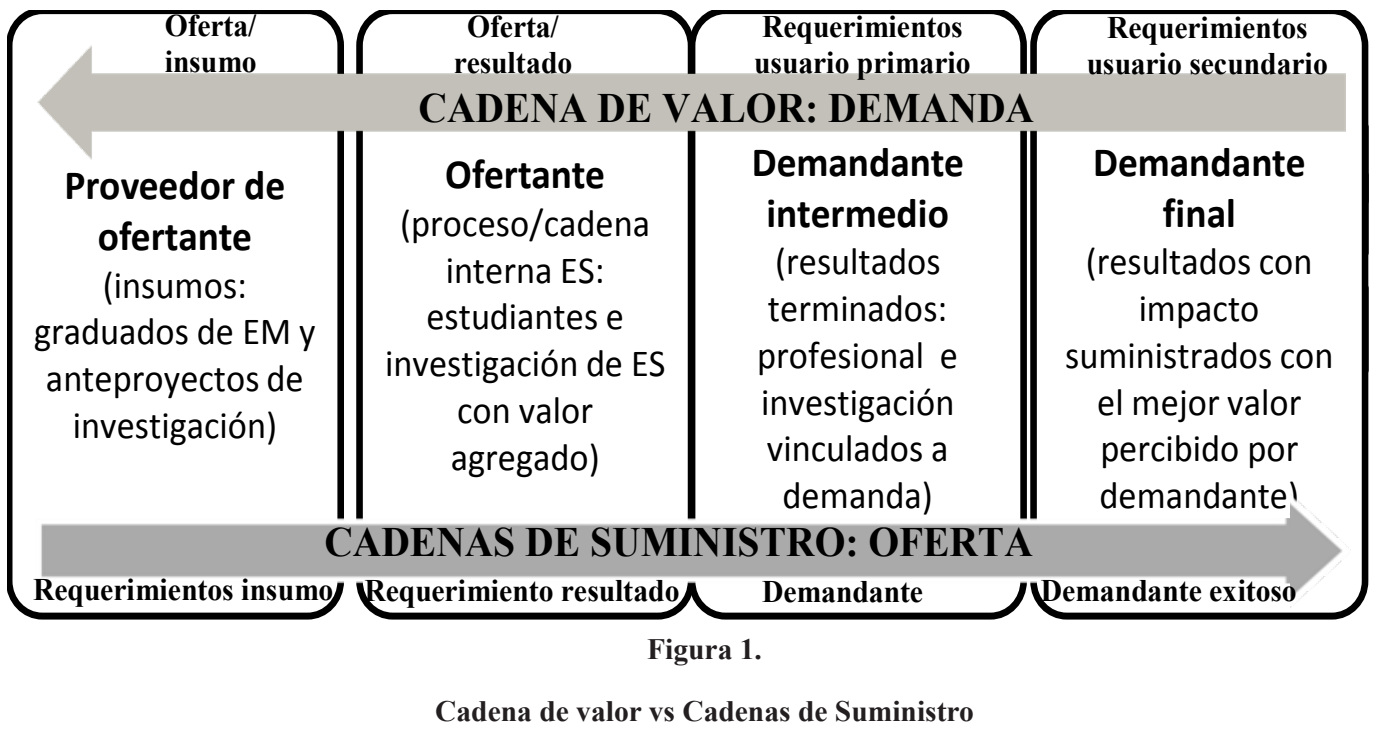

Así pues, son los mismos actores e insumos tanto para ambas cadenas de suministro como para la cadena de valor. En el caso de la ES, la oferta la componen los proveedores de insumos de ES y los ofertantes de ES, y la demanda la componen los usuarios primarios o beneficiarios/demandantes intermedios de los resultados terminados (ej. profesional y resultado de investigación) tales como estudiantes, familia, patrocinadores, propiedad intelectual (PI), colegios profesionales, instituciones de ES (IES), etc.), así como los demandantes finales o usuarios secundarios, tal como empleadores. Por tanto, la diferencia fundamental entre ambas cadenas es la dirección del flujo entre la oferta 
y la demanda. La cadena de valor se enfoca hacia atrás, creando valor a los ojos del demandante/ beneficiario (Figura 1, flujo derecha izquierda). Por otro lado, la cadena de suministro se enmarca hacia adelante, integrando procesos del ofertante, mejorando la eficiencia y reduciendo el desperdicio (Figura 1, flujo izquierda derecha).

Por otro lado, algunos autores ven al valor como perceptual, alrededor del movimiento de recursos, siendo acumulado por ambos actores de la transacción (demandantes y ofertantes). En esta perspectiva, la cadena de valor opera en ambas direcciones, con los demandantes, obteniendo valor de los bienes y servicios suministrados, mientras que los ofertantes derivan lo suyo de los recursos financieros, pagos, estabilidad, peticiones que algunos de sus demandantes proveen. Aquí el valor es una cualidad relacionada con los demandantes que ocurren a distintos puntos de intercambio, dejando una cadena de articulaciones que mueve recursos entre los socios (Ramsay, 2005).

Además, existe también el concepto de que la gestión de la cadena de suministro es la integración no sólo de la cadena de suministro, con sus procesos desde el proveedor que suministra productos, servicios e información, sino también de la cadena de valor, al buscar añadir valor a demandantes y socios. Con ello se elimina la distinción entre cadena de valor y la de suministros, porque la cadena de suministro evoluciona, integrando flujos de valor y de suministro. (Lambert et al., 1998; Abrahamson y Farichild, 1999.).

Ya sea que se vea como una cadena de recursos con flujo de fondos moviéndose desde un extremo (demanda) y suministro desde el otro (oferta), o como dos cadenas complementarias (una de valor y la otra de suministro), o como una gestión de la cadena de valor integrando ambas, crear una cadena eficaz y eficiente requiere el alineamiento entre la cadena de demanda (lo que el cliente quiere, enfocándose en los valores añadidos, en la innovación del desarrollo de profesionales e investigación y en su mercadeo) y la cadena de suministro (lo que se produce, cuyo enfoque primario es la reducción de costos/desperdicios y el logro de la excelencia operacional).

Debido a que el valor se deriva de las necesidades de beneficiarios/demandantes, las actividades que no contribuyen a cumplir dichas necesidades se les consideran como desperdicio que no añade valor 
(Feller et al., 2006). Si tomamos las tareas y funciones que operan en la “industria de la educación”, las actividades de mejora de procesos pueden determinar el desperdicio disponible para reducirlo o, en su defecto, eliminarlo. La esencia estratégica de las cadenas de suministro, docencia e investigación, se debe enfocar en la excelencia operativa, buscando dinamizar los procesos que generan profesionales y proyectos de ES, que los demandantes/beneficiarios valoran y gastando menos recursos, por lo que aumenta el margen entre el valor del demandante y el costo de entrega.

Por su lado, la cadena de valor, vinculación a la demanda de ES, debe enfocarse en estrategias de innovación, mercadeo y de mejora continua del valor agregado, que aumenten las percepciones del valor de los profesionales y resultados de investigación de ES, optimizando de manera innovadora la percepción de lo que se entrega. En ambos casos, el fundamento para el incremento del rendimiento de ES debe ser mejorar el margen entre el valor percibido y el gasto de entrega.

En relación a la combinación de ambos tipos de cadenas (suministro y valor), la literatura (Ortega, 2011; Ortega y Eguía, 2011) propone el modelo de un Sistema Integrado de Valor y de Suministro de Educación Superior (SIVSES), que integra una cadena de valor y dos de suministro de ES de Honduras, que incluye los insumos/entradas de ES (ej. graduados de educación media (EM)), el proceso de ES, las salidas/resultados de la ES. Dicho modelo considera todos los actores de ES (proveedores de insumos, ofertantes/universidades y demandantes/beneficiarios de resultados) para entender como sus interrelaciones contribuye al éxito de las tres funciones fundamentales de ES: docencia, investigación y vinculación a la demanda de ES. Aunque dicho modelo teórico es mejor y más completo que modelos anteriores en la literatura (que sólo presentan una perspectiva parcial tal como el modelo de Habib (2010) de las cadenas de suministro), la literatura no presenta formas para su gestión y operación.

Así pues, el presente estudio plantea la siguiente pregunta de investigación: ¿existe un modelo de gestión de operaciones para el modelo del SIVSES, que incluya sus dos cadenas de suministro (docencia e investigación) como la oferta de ES y una cadena de valor sobre la vinculación a la demanda de ES? Ello se hace con el objetivo de presentar una operativización y gestión del SIVSES, por medio de una investigación exploratoria. Para ello, en la siguiente sección (2) se consideran todos los actores involucrados y sus relaciones (proveedores de insumos, ofertante de ES, demandante de resultados 
de ES), así como el insumo mismo y el resultado de ES (incluido el proceso de transformación). Con dichos elementos, se hacen las propuestas de gestión de operaciones del modelo del SIVSES. En la sección (3), se construyen los elementos de gestión del modelo SIVSES, que incluye el desarrollo y evaluación de la docencia y la investigación, considerando los niveles de decisión (estratégico, de planificación y de operaciones). Después (4), se deja establecido el modelo de gestión operaciones del estudio, con algunas de sus posibles relaciones. Finalmente, el último apartado (5) presenta las conclusiones.

\section{FUNDAMENTOS DEL MARCO REFERENCIAL Y PROPOSICIONES}

Desde la perspectiva de la cadena de valor es necesario definir no solo los insumos principales (que son parte misma de las cadenas de suministro), sino también los insumos de las actividades de apoyo de dichas cadenas, los resultados primarios (dirigido a los demandantes de ES), secundarios (ej. de docencia son los graduados de ES que vuelven como estudiantes de postgrados, otras carreras, educación continua, etc.) y terciarios (ej. de docencia son los graduados que pasan a ser parte del proceso de ES y/o del proceso de proveedor de insumos de ES tal como una institución de educación media (IEM)), y el proceso interno de ES (para más detalles ver el modelo SIVSES de Ortega y Eguía, 2011). Todo ello representa cinco componentes significativos de tres cadenas, dos de suministro y otra de valor, cuya planificación y operación interrelacionada es fundamental para reunir las expectativas de los socios, en lo que sería un sistema de educación superior. Como puede verse en la Tabla 1, algunos profesionales pueden continuar en la ES como estudiantes de postgrado, lo que permitiría que una Institución de ES (IES) pueda funcionar como un sistema de suministro flexible, con una dualidad insumo-resultado (entrada-salida), que presenta la oportunidad de un insumo (ej. estudiante de postgrado) procesando otro insumo (estudiante de grado, investigación). Además, se puede ver resaltado en negrita en las columnas de suministro (docencia e investigación), que la ES tiene otras dos peculiaridades: 1) que proveedores de insumos, que conocen el estado de los insumos, pueden ser también usuarios/demandantes de los resultados suministrados en el proceso de ES; y 2) que los estudiantes de ES son en sí mismo insumos del suministro de docencia, que como estudiantes están demandado, el resultado final de ser graduados de ES, manifestado en profesionales cualificados. 
Tabla No 1.

Componentes de cadenas de valor y de suministro (docencia e investigación)

\begin{tabular}{|c|c|c|c|}
\hline COMPONENTES & $\begin{array}{l}\text { Suministro de } \\
\text { docencia }\end{array}$ & Suministro de investigación & $\begin{array}{l}\text { Valor de } \\
\text { vinculación ES- } \\
\text { demanda de ES }\end{array}$ \\
\hline $\begin{array}{l}\text { 1. Proveedor de } \\
\text { insumos a ofertante } \\
\text { de ES }\end{array}$ & $\begin{array}{l}\text { Estudiante } \\
\text { autofinanciado, IEM, } \\
\text { tecnológico, IES, } \\
\text { familia, organización } \\
\text { privada o pública por } \\
\text { una beca, estudiante } \\
\text { de postgrado, } \\
\text { empleador }\end{array}$ & $\begin{array}{l}\text { Facultad }^{1} \text { (grado y posgrado), } \\
\text { Educación Media/Ciencia y } \\
\text { Tecnología/DES, organización } \\
\text { privada o pública }\end{array}$ & $\begin{array}{l}\text { Búsqueda de } \\
\text { mejora de calidad } \\
\text { en insumos } \\
\text { y relaciones, } \\
\text { involucramiento en } \\
\text { requerimientos de } \\
\text { materia prima }\end{array}$ \\
\hline 2. Insumos provistos & $\begin{array}{l}\text { Fondos, estudiantes } \\
\text { (incluido maestro) }^{2}\end{array}$ & $\begin{array}{l}\text { Fondos, proyecto externo e } \\
\text { interno }\end{array}$ & $\begin{array}{l}\text { Medición de calidad } \\
\text { de insumos }\end{array}$ \\
\hline $\begin{array}{l}\text { 3. Ofertante ES/ } \\
\text { Universidad: proceso de } \\
\text { valor y de suministro }^{3}\end{array}$ & $\begin{array}{l}\text { Facultad, programa } \\
\text { acreditado, gestión } \\
\text { del conocimiento, } \\
\text { instalación, gestión de } \\
\text { la calidad total }\end{array}$ & $\begin{array}{l}\text { Proyectos de investigación, } \\
\text { centro de investigación }\end{array}$ & $\begin{array}{l}\text { Medición y mejora } \\
\text { de valor que agregan } \\
\text { los socios internos } \\
\text { de ES a estudiantes e } \\
\text { investigaciones }\end{array}$ \\
\hline $\begin{array}{l}\text { 4. Usuario/demandante } \\
\text { intermedio (estudiante } \\
\text { como profesional } \\
\text { y patrocinador de } \\
\text { investigación/proyectos) }\end{array}$ & $\begin{array}{l}\text { Familia, estudiante } \\
\text { como profesional } \\
\text { vinculado a demanda, } \\
\text { patrocinadores de } \\
\text { becas (IES, IEM, } \\
\text { tecnológico), colegios } \\
\text { profesionales } \\
\text { universitarios }\end{array}$ & $\begin{array}{l}\text { Resultado de investigación } \\
\text { vinculado a demanda, } \\
\text { organización patrocinadora } \\
\text { de proyectos de investigación } \\
\text { (Facultad, Educación Media, } \\
\text { ES, Ciencia y Tecnología, } \\
\text { organización privada, etc.) }\end{array}$ & $\begin{array}{l}\text { Percepción de } \\
\text { valor de graduados } \\
\text { y resultados de } \\
\text { investigación, } \\
\text { medición de calidad, } \\
\text { mercadeo }\end{array}$ \\
\hline 5. Demandante final & Sociedad, empleador & $\begin{array}{l}\text { Sociedad, sector implementado } \\
\text { de investigación, desarrollo e } \\
\text { innovación }(\mathrm{I}+\mathrm{D}+\mathrm{i})\end{array}$ & $\begin{array}{l}\text { Indicadores de } \\
\text { impacto aportados } \\
\text { (vinculación a } \\
\text { demanda por } \\
\text { tasas de retorno, } \\
\text { empleabilidad), } \\
\text { mercadeo, } \\
\text { aplicabilidad } \\
\text { (innovación y } \\
\text { desarrollo de } \\
\text { investigaciones) }\end{array}$ \\
\hline
\end{tabular}

1 Puede ser otra unidad académica interna.

2 Maestros de ES como parte del servicio de apoyo primario y/o de EM como parte del servicio de apoyo primario a la cadena de valor de EM que permita la mejora de sus graduados como estudiantes de ES.

3 Ver proceso de cadena de valor y relaciones (Ortega y Eguía, 2011).

4 El valor añadido permite evaluar al ofertante sobre la calidad, volumen y nivel de investigaciones derivadas durante el suministro de insumos a lo largo de su procesamiento académico. Ello incluye evaluar la calidad de los proyectos de Tesis en todos los niveles. 
En este marco de referencia, se formula un sistema multinivel y parcialmente bidireccional (dualidad proveedor-demandante) para la ES (Figura 2). Dado que un solo actor (una universidad por sí misma) no puede lograr un proceso eficiente y eficaz en la ES, es necesario articular los diferentes actores involucrados, para lograr así los resultados finales requeridos, sabiendo que cada actor como unidad de trabajo es responsable por un tipo de acabado/entregable en específico. Sin embargo, existen actores a niveles múltiples en los procesos de los productos intangibles de ES (siendo principalmente del sector de servicios), donde el mismo actor juega el papel de proveedor de insumos, de insumo mismo y de usuario/demandante (ej. los estudiantes pueden ser al mismo tiempo proveedores de insumo, insumo y demandante).

Así pues, en este estudio se han identificado a los proveedores de insumos de ES, a los demandantes intermedios multinivel (usuario primario que demanda y se relaciona directamente en el proceso para que se les agregue valor a los insumos hasta que sean resultados terminados), al ofertante de servicios de ES, y al demandante final (usuario secundario de resultados de ES terminados). Además, se definen entradas/insumos provistos, demandantes de ES consumiendo salidas/resultados, demandantes proveyendo entradas (insumos) ${ }^{5}$, usuarios siendo parte del proceso de oferta de ES (pasan como profesorado o personal de apoyo a la ES y/o a la EM como proveedor de insumos), salidas/resultados suplidos (profesional y resultados de investigación de ES), suministro de estudiantes de ES, que interactúan con la sociedad (trabajan y estudian, dejan de estudiar para trabajar, algunos reingresan a la ES como estudiantes, etc.), y potencial suministro de insumos de estudiantes (graduados de EM con los requerimientos de ES) y de anteproyectos de investigación (de desarrollo e innovación que se realizan fuera de la ES), que son viables como insumos de ES.

5 Aquí se incluye a estudiantes que se proveen como insumos y son demandantes a ser profesionales graduados o postgraduados y algunos proyectos longitudinales de investigación. Además, de resultados de ES como profesionales e investigaciones de ES que contribuyen en la graduación de estudiantes de EM que son insumos de ES. 


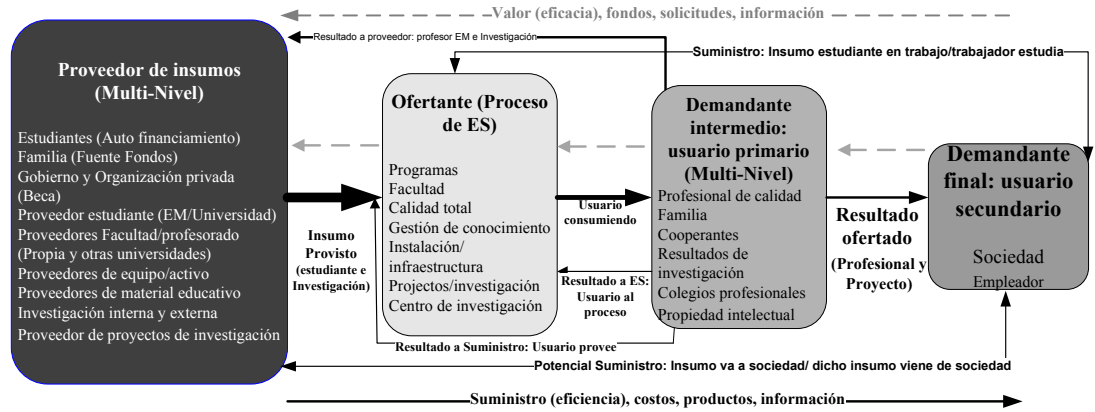

Figura 2.

Flujo de suministro y valor multinivel y multidireccional

(Adaptado de Habib y Jungthirapanich, 2010)

La integración total del sistema, tanto hacia adelante desde los proveedores de insumos, pasando por los ofertantes de ES hasta los demandantes de ES (beneficiarios/usuarios), como hacia atrás desde los demandantes de ES hasta los proveedores (pasando siempre por los ofertantes), es clave para su eficiencia y eficacia. Así pues, la Figura 3 muestra claramente dos cadenas de suministro (docencia e investigación) y una de valor (vinculación a la demanda de ES) que, juntas, forman los elementos del modelo teórico SIVSES propuesto en la literatura (Ortega y Eguía, 2011), que son fundamento del presente estudio. Para ello, el modelo conceptual presenta dos insumos principales, estudiantes y propuestas/anteproyectos de investigación. Ambos se convierten eventualmente en dos productos intangibles en dicho sistema (en algunas ocasiones tangibles como parte de la propiedad intelectual/PI), profesionales y resultados de investigación vinculados (valorados por la demanda). Ambos resultados finales del sistema mencionados ${ }^{6}$ deben ser entregados al demandante/beneficiario final (sociedad) por las dos cadenas de suministro antes mencionadas (docencia e investigación), con el mayor valor percibido (cadena de valor). La Figura 3 ilustra la perspectiva holística de las tres cadenas.

6 De existir una sistematización que permita la integración docencia-investigación, las tesis de grado y de posgrados enmarcadas en proyectos de investigación pueden ser usadas para medir simultáneamente la calidad de los graduados y de los resultados de investigación de ES. 

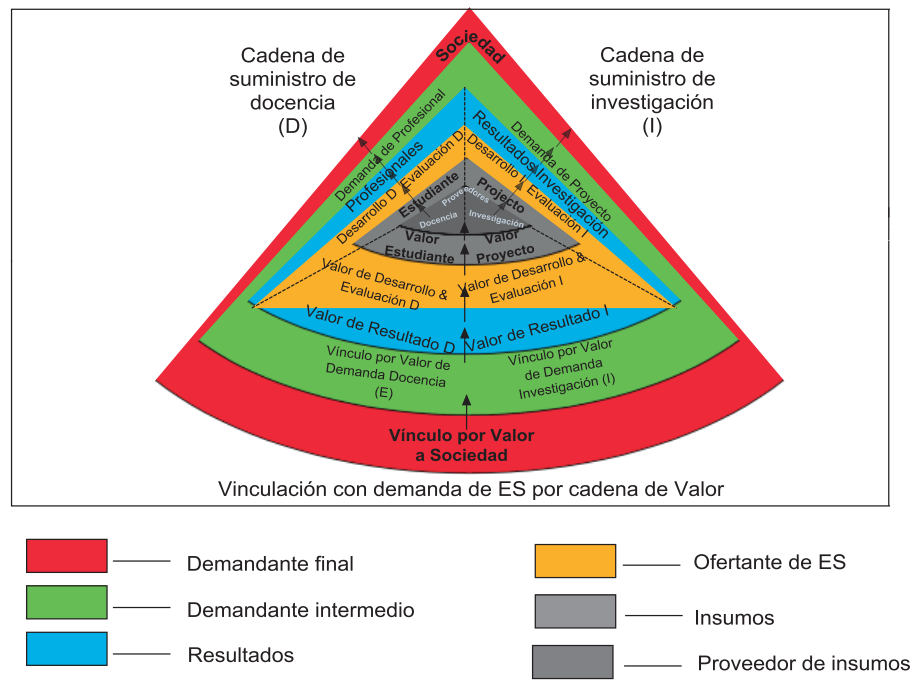

Figura 3.

Suministro de docencia e investigación y valor de vinculación a demanda

(Adaptado de Habib y Jungthirapanich, 2010 y Ortega, 2011)

Por lo tanto, siguiendo el flujo de las cadenas de suministro (Figuras 2 y 3), a continuación se detallan

los componentes del sistema no sólo de la oferta de ES, sino también de la demanda de ES. Para ello, se parte del proveedor de insumos, se continúa con el ofertante de ES, y se concluye con el demandante de ES. Finalmente, se hacen las proposiciones respectivas de una gestión de operaciones del modelo SIVSES propuesto por Ortega y Eguía (2011).

\subsection{Proveedor Multinivel}

Por el lado de la oferta, la ES tiene proveedores multinivel de insumos/materia prima para ofertantes. Aunque los proveedores se pueden dividir principalmente en las dos cadenas de suministro de ES, docencia $^{7}$ e investigación (Habib, 2010; Ortega y Eguía, 2011), más allá de los insumos provistos, estudiantes y proyectos de investigación, respectivamente, este estudio permite categorizar a los proveedores en otros dos grandes grupos: proveedores de insumos primarios a los suministros de docencia e investigación, y proveedores de insumos secundarios que proveen al proceso de ES (Figura 4).

7 Oficialmente, en Honduras la única universidad que se acepta para el escalafón de docentes de Educación Media (EM) (proveedor del insumo de graduados de EM) es la Universidad Pedagógica Nacional Francisco Morazán (UPNFM), relegando a que cualquier otro profesor no graduado en la misma sea ascendido, aunque se hubiera graduado en la mejor universidad del mundo y/o que tuviera doctorado. Sin embargo, se espera poder medir la eficacia y eficiencia de que sólo una universidad suministre los docentes de EM. 
Proveedores de insumos primarios. Proveen materia prima fundamental para la oferta de profesionales e investigaciones de ES.

- Humano: En el área de docencia tal como los estudiantes (ej. instituciones de EM, universidades, tecnológicos, el estudiante mismo, etc.).

- No humano: En el área de investigación tal como proyectos internos (ej. postgrados y pregrados de facultades, centros de investigación, otras unidades) y externos (ej. cooperantes, interuniversidades, etc.).

- Fondos ${ }^{8}$ para docencia y/o investigación: Estudiantes autofinanciados, fuentes de financiamiento de estudiantes (ej. familia, empleadores, becas de organizaciones públicas y privadas, empleadores, préstamos), fuentes de proyectos de investigación (ej. autofinanciamiento de universidad, fondos de investigación externos, el Gobierno, organizaciones privadas, etc.)

Proveedores al proceso de ES. Proveen materia prima secundaria, que sirven de apoyo en el proceso de la materia prima fundamental.

- Humano9: Áreas de docencia e investigación tales como el profesorado ${ }^{10}$ (universidades) y el personal de apoyo tanto administrativo como técnico (ej. universidades, instituciones de EM y otros)

- No humano: Recursos de docencia e investigación tales como bienes y equipo (ej. mobiliario, TIC, etc.) y materiales de educación (ej. papelería, materiales de docencia e investigación, etc.).

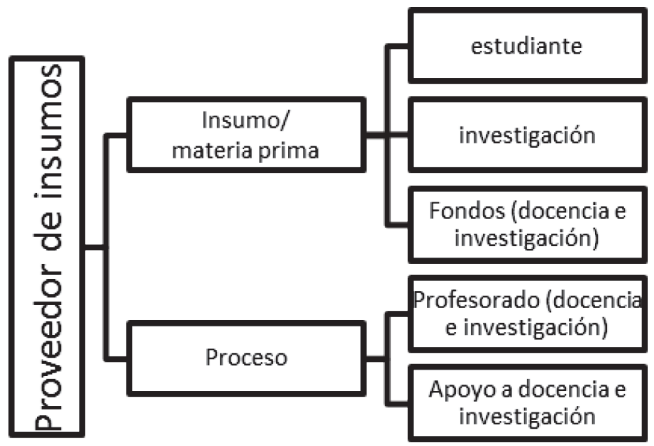

Figura 4.

Proveedor de insumos de ES: materia prima y proceso

(Adpatado de Lau, 2007)

8 Dado la peculiaridad de la ES, donde muchos de los proveedores son también demandantes que proveen los fondos (parcial o total), algunos para docencia y otros para investigación.

9 "Las inducciones" previas al ingresar, no sólo de los docentes sino también de todo profesional de ES en el mercado laboral se pueden considerar como un reproceso que se deberán medir en la siguiente etapa empírica en proceso del proyecto, pero que van más allá de este artículo teórico.

10 El profesor e investigador son clave en el proceso fundamental de docencia e investigación de ES. 


\subsection{Ofertante de profesionales y de resultados de investigación de ES}

En este estudio se considera a la ES como un ofertante/suministrador tanto de profesionales de ES, como de productos y servicios de investigación. Sin embargo, son varios los factores que identifican a la ES más dentro del sector de servicios (Habib, 2010), entre ellos:

- Distintos programas acreditados

- $\quad$ Facultad (profesorado investigador)

- Instalaciones e infraestructura (uso)

$\diamond$ Aulas

$\diamond$ Internet

$\diamond$ Laboratorio

$\diamond$ TIC

$\diamond$ Biblioteca (incluida digital)

$\diamond$ Base de datos en línea \& Revista Internacional

$\diamond$ Aprendizaje presencial, virtual, y a distancia

- Gestión del conocimiento

- Gestión de la calidad total

- Proyectos de investigación (internos y externos)

- Centros de investigación

- Enseñanza y aprendizaje como medio para lograr que estudiantes se hagan profesionales

- Conocimiento, habilidades y experiencia de estudiantes graduados a estudiantes de pregrado.

- Vinculación de docencia e investigación con los demandantes/sociedad para lograr valores percibidos mayores.

Por otro lado, en el proceso de oferta de servicios de ES se identifican dos tipos de actividades, a saber (ver Figura 5): 1) funciones fundamentales de las dos cadenas de suministro y la cadena de valor por la vinculación (involucradas directamente con la creación y entrega de profesionales y resultados de investigación de ES); y 2) actividades de apoyo (aunque pueden no estar directamente relacionadas a proveer profesionales y resultados de investigación de ES, son ejes transversales, con el potencial para incrementar la eficacia y eficiencia de las funciones fundamentales docencia, investigación y vinculación a demanda). 


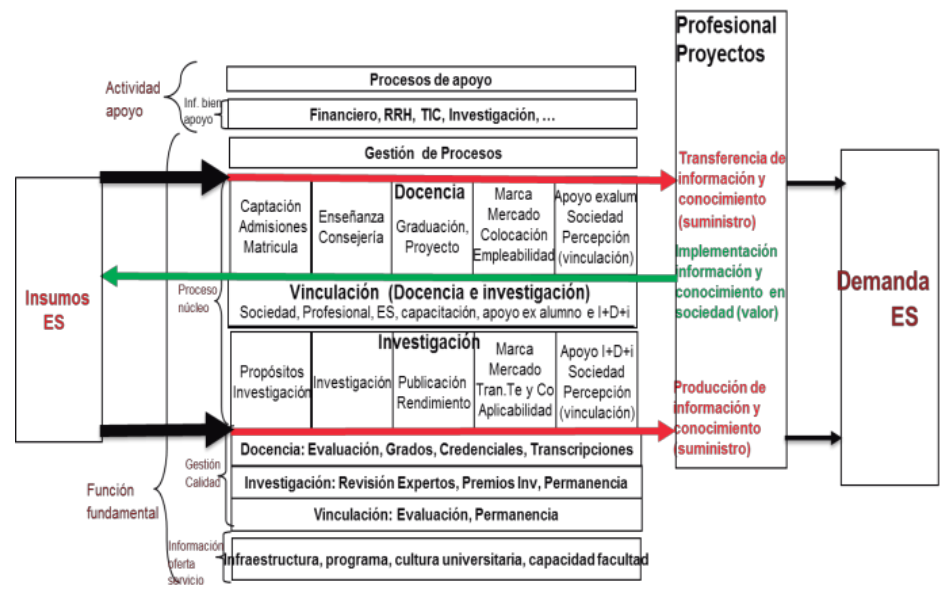

Figura 5.

Ofertante de ES: proceso de suministro y de valor

(Adaptado de Porter, 1985)

Por otro lado, en la Figura 6 se puede ver una agrupación de indicadores y relaciones clave de la cadena de valor (vinculación a demanda) y de las dos de suministro de oferta (docencia e investigación) de la ES (Pathak y Pathak, 2010).

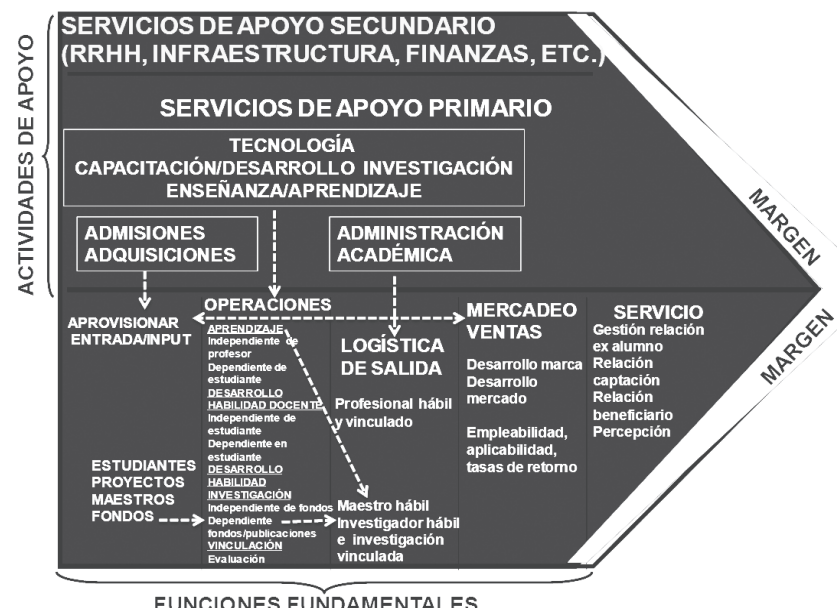

Figura 6.

Indicadores y relaciones de funciones y actividades del ofertante de ES

(Adaptado de Pathak y Pathak, 2010; Porter, 1985) 
La Figura 6 resalta las funciones y actividades fundamentales y las de apoyo de las tres cadenas que se explican en los siguientes dos sub-epígrafes.

\subsubsection{Relaciones e indicadores de actividades fundamentales de ES}

- Logística de entrada: Es el ingreso o provisión, donde se recibe y almacena la materia prima (estudiantes y proyectos de investigación) y recursos (profesorado y fondos (principalmente para investigación)). La distribución al área de producción es según la necesidad y capacidad de captar insumos para preparar profesionales y/o realizar proyectos de investigación (ej. admisiones, propósitos de investigación, matrículas, subvenciones) $)^{11}$.

- Operaciones: Proceso de transformar insumos en profesionales, productos y servicios terminados de ES (ej. docencia, investigación, consejería).

$\diamond$ Aprendizaje: Independiente del profesor y dependiente del estudiante.

$\diamond$ Desarrollo de habilidades docentes y profesionales: independiente del estudiante, pero dependiente en estudiante.

$\diamond$ Desarrollo de habilidades investigadoras e investigaciones: Independiente de fondos y/o dependiente de fondos que produzca resultados en publicaciones, PI, desarrollo e innovación. $\diamond$ Vinculación a demanda: Evaluación de ambos procesos de las funciones de las cadenas de suministro de la oferta (docencia e investigación) en la búsqueda de mejores valores percibidos por beneficiarios de ES (usuarios intermedios y finales).

- Logística de salida: Almacenamiento y distribución de resultados terminados (profesional, publicación, colocación, rendimiento). El proceso anterior (operaciones) debe buscar como dos tipos de salidas: 1) que el aprendizaje arroje resultados vinculados a la demanda (profesionales y maestros hábiles por el valor añadido en la ES); y 2) que la dependencia de fondos y las publicaciones lleve a investigadores hábiles y resultados de investigación vinculados (valor

11 Es importante considerar que el SIVSES (Ortega y Eguía, 2011) puede presentar deficiencias en el inventario del proceso de docencia de ES, donde exista ya sea una masa crítica de estudiantes rezagados (ej. estudian y trabajan, dejan de estudiar y retornan con el tiempo, etc.) o de graduados de EM que tienen las cualificaciones para estudiar ES pero no lo hacen. Deficiencias en el inventario del proceso de la investigación de ES, pueden darse cuando las IES no se articulan con el gobierno, empresa privado o la sociedad en espacios comunes de consultorías o investigación, desarrollo e innovación ( $\mathrm{I}+\mathrm{D}+\mathrm{i})$. Tanto estas deficiencias como los insumos en tránsito (estudiantes e investigaciones) pueden ser valorados para un flujo más eficaz y eficiente, adaptando métodos contables tales como FIFO y LIFO desde una perspectiva de inventarios en sus diferente etapas del proceso de ES: resultados producidos (profesionales y resultados de ES), sus insumos, y sus partes o componentes. Sin embargo, dicha propuesta va más allá de los objetivos de este estudio fundamental y se dejan para el estudio empírico posterior. 
añadido en la ES). Todo ello con una ES vinculada a sus beneficiarios/sociedad que perciban el mayor valor posible.

- Mercadeo y ventas: Identificación de necesidad del cliente (demandante) y generación de entregas de resultados de ES (vinculación a demanda, captación, transferencia de tecnología y de conocimiento). Para ello, es necesario desarrollar una marca distinguible y el mercado objetivo de profesionales y de resultados de investigación. Además, por medio de la vinculación a la demanda, se debe lograr aumentar la percepción del valor de los resultados por los demandantes. Debe mantener una relación bidireccional con el componente de entrada, como se aprecia en la flecha con líneas punteadas.

- Servicio: Apoyo a beneficiarios y post-servicio de profesionales, productos y servicios (ej. vinculación a la demanda, apoyo académico, servicio a comunidad, apoyo a egresados, $\mathrm{D}+\mathrm{i})^{12}$. La vinculación debe lograr una gestión de relaciones con proveedores de materia prima, con ex alumnos y con usuarios/beneficiarios, que permita sistematizar una relación de la ES como captador de insumos, cuyos resultados puedan ser entregados.

\subsubsection{Relaciones de actividades de apoyo}

Para una mayor eficiencia, las actividades de apoyo se pueden clasificar en dos grandes subgrupos:

a. Actividades secundarias

- Recursos humanos

- infraestructura/instalaciones.

b. Actividades primarias:

- Adquisiciones y admisiones, que están directamente relacionadas con la entrada de insumos.

- Tecnología, capacitación y desarrollo de investigación, y enseñanza/aprendizaje, que apoyan principalmente a las operaciones fundamentales de ES.

- Administración académica, que apoya para una mejor logística de salida.

12 El post-servicio incluye no sólo re-procesos para la academia por deficiencias de sus resultados en relación a una posible desarticulación oferta-demanda de ES, que afectan las tasas de retorno de investigaciones (aplicabilidad) y profesionales (empleabilidad) de ES y por tanto la inversión marginal en educación de dichos suministros, sino también para captar estudiantes de post-grados y proyectos de investigación, así como darle seguimiento en general a los resultados de ES a lo largo de la vida (educación e investigación continua). 


\subsection{Demandante de ES: usuarios de resultados}

\subsubsection{Demandantes intermedios: usuarios primarios}

El demandante intermedio es el que demanda en primera instancia el resultado de ES, antes de entregar dicho resultado a la sociedad (ej. empleador). Regularmente está involucrado en el proceso para que el insumo sea un resultado terminado. Se identifican dos tipos de demandantes intermedios: 1) estudiantes demandando docencia para estudios ad-hoc o para ser profesionales de $\mathrm{ES}^{13}$, y 2) universidad-colaboradores demandando investigación/proyectos y profesionales (ej. colegios profesionales universitarios, organizaciones aportantes de becas, etc.). Ambos tipos de demandantes presentan una dualidad demandante-proveedor, al jugar simultáneamente los dos roles (Figura 7), que se explica a continuación.

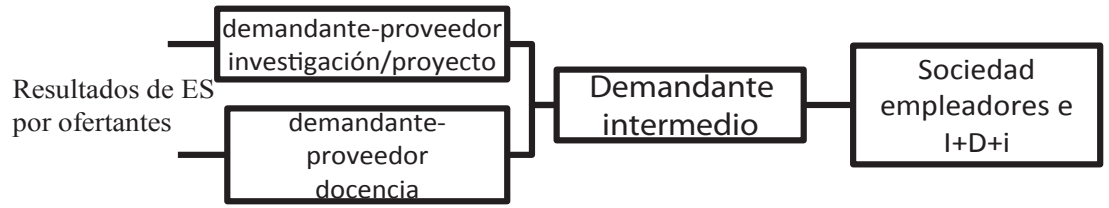

Figura 7.

Demandantes de la ES: intermedios y final

(Adaptado de Lau, 2007)

\section{Demandantes de docencia}

- Dualidad demandante-proveedor de insumos ${ }^{14}$ : flujo bidireccional que contribuye al desarrollo de estudiantes como graduados profesionales.

$\diamond \quad$ Donde graduados de EM como estudiantes de ES demandan ser profesionales de ES (los tres niveles de resultados de la Sección 2: primarios, secundarios y terciarios)

$\diamond \quad$ Cuando profesionales (graduados de ES) vuelven a demandar como estudiantes de postgrado o de otro tipo de instrucción (resultados secundarios)

$\diamond \quad$ Cuando existe un patrocinador de becas, apoyo familiar, instituciones de educación superior (IES's), etc. (los tres niveles de resultados).

13 Pon un lado, puede ser nivel técnico, grado, posgrado (maestría y doctorado), especialidad, etc., o por otro puede ser educación continua tales como capacitaciones, certificados, diplomado, etc.

14 Operativamente, el estudiante de ES juega un papel triple, único en cadenas de suministro de cualquier otro sector, al ser no sólo un proveedor de insumo, sino también el insumo mismo que se transforma en el resultado más importante del proceso de ES (profesional), así como el demandante primario de dicho resultado. 


\section{Demandantes de investigación/proyectos}

- Dualidad demandante-proveedor de insumos: flujo bidireccional por la obtención de resultados y conocimientos de $\mathrm{I}+\mathrm{D}+\mathrm{i}$ (investigadores, publicaciones, conclusiones, proyectos terminados, etc.)

$\diamond \quad$ Para propia universidad, para organizaciones patrocinadoras y colaboradores de proyectos de $\mathrm{I}+\mathrm{D}+\mathrm{i}$, etc. (los tres niveles de resultados).

$\diamond \quad$ Se identifican líneas y programas permanentes y longitudinales de investigación. Por ej. proyectos anteriores son necesarios de nuevo en rondas subsecuentes de proyectos (resultados secundarios).

\subsubsection{Demandante final: usuario secundario}

El estudio toma a la sociedad como el beneficiario/demandante en la instancia final desde una perspectiva de las cadenas de suministro (ver Figura 7). Es el demandante del usuario primario de profesionales y resultados de investigación. Dado que la ES es parte intrínseca de la sociedad, los resultados finales de su sistema (profesionales y resultados de investigación/proyectos de desarrollo e innovación vinculados a la demanda) son entregados inevitablemente a la sociedad (principalmente a los empleadores y a sectores donde se implementan proyectos de investigación). Así pues, se pueden ver dos tipos principales de contribuciones a la sociedad (Habib, 2010): 1) el capital intelectual por profesionales e instruidos trabajando con todo tipo de empleadores (incluido emprendedurismo/ autoempleo); y 2) proyectos de I+D+i de ES ejecutados/implementados en sectores de la sociedad.

Siendo los demandantes la fuente del flujo valor, sus percepciones son la principal referencia en el modelo de SIVSES, para lograr la mejor valoración. Así pues, para alcanzar resultados de ES más efectivos es necesario añadir los valores más altos en cada paso del sistema, y/o usar un enfoque de mercadeo y/o innovación en mejorar las percepciones de los demandantes.

Como caso especial, los demandantes que simultáneamente proveen insumos (ej. estudiantes) pueden servir para monitorear permanentemente valores añadidos por distintas etapas del proceso de ES, dado que pueden saber en qué condición dichos insumos estaban inicialmente. Por otro lado, cuando estudiantes de ES se gradúan, al hacer uso de autoevaluaciones, se pueden aproximar márgenes entre valores percibidos de ES y gastos para lograrlos. 
Basado en todos los elementos anteriores del marco conceptual de proveedores de insumos, y ofertantes y demandantes de ES se hacen las siguientes dos proposiciones, enfatizando el uso del modelo de SIVSES de Ortega y Eguía (2011) de la Figura 3 que plantea que las dos cadenas de suministro de ES (docencia e investigación) por Habib y Jungthirapanich (2010) deben estar permanentemente vinculadas a la demanda de ES (sociedad y empleadores). Para ello, el modelo SIVSES considera también elementos de la vinculación de ES-demanda de ES como una cadena de valor de Porter (2005), aplicada a ambas cadenas de suministro, así como todos los flujos de resultados y deficiencias del sistema (ej. fricciones del proceso de Es y del mercado) (ver Figura 2):

Proposición 1. Existen las condiciones de estructura, procesos y recursos que permitan la articulación entre los elementos del SIVSES.

Proposición 2. Hay un modelo de gestión de operaciones que permita balancear la oferta y demanda de ES, por medio de las relaciones entre los actores, insumos y resultados del SIVSES.

Estas proposiciones se fundamentan en la tesis de que las cadenas de ES, una de valor y las otras dos de suministro, deben ser gestionadas y operadas de manera integrada, para que haya mayor eficiencia y eficacia de la ES. Ambas proposiciones son críticas si se quiere completar una teoría del balance entre la oferta y demanda de los resultados de ES, considerando que debe ser guiada por una demanda muy heterogénea con una cartera de beneficiarios de la ES muy variada, demandando distintos resultados (ej. puede haber una demanda de profesionales y/o investigaciones especializadas, multidisciplinarias, generales o básicas, etc.). Además, estas proposiciones deben ser evaluadas en el contexto de publicaciones anteriores dentro de las cadenas de ES. A continuación se revisa la Proposición 1 y después la Proposición 2 (sección 4). 


\section{ARTICULACIÓN DEL MODELO SIVSES}

Como ofertante de profesionales y resultados de investigación, se identifican dos partes principales de la ES, que permiten una garantía de satisfacción a los socios, actores y demandantes de la ES en general en un sistema integrado de valor y de suministro de ES (SIVSES), no sólo para la docencia sino también para la investigación: desarrollo y evaluación, vinculados a la demanda por una cadena de valor (Habib y Jungthirapanich, 2010). Así pues, tomado la Figura 8, el desarrollo y evaluación de la ES se puede representar en un modelo simplificado del flujo multidireccional y multinivel de suministro-valor (eficiente y eficaz).

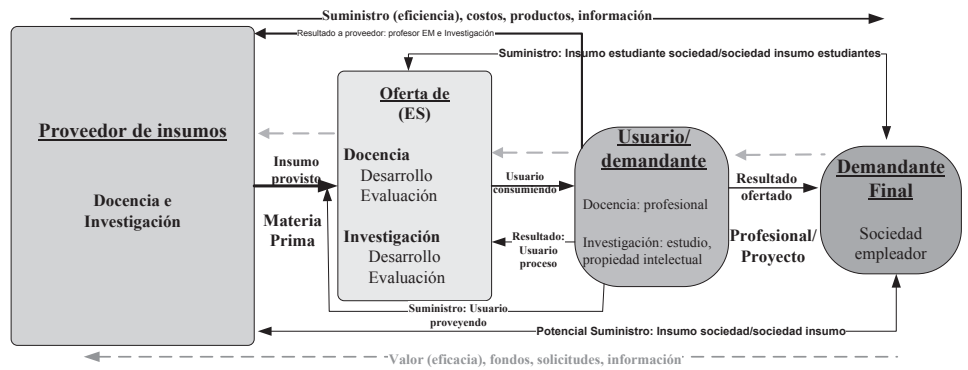

Figura 8.

Desarrollo y evaluación del suministro de docencia y de investigación

(Adaptado de Habib y Jungthirapanich, 2010)

Además, desde una perspectiva académica, en el desarrollo y evaluaciones de la docencia e investigación, vinculadas a la demanda de ES, se pueden considerar cuatro aspectos de la gestión eficaz y eficiente de ES (Habib y Jungthirapanich, 2010):

1. Programas/currículo: Facultades, departamentos y carreras para el desarrollo docente e investigador. Además, para la evaluación se tienen programas de gestión de la calidad de la investigación y la docencia.

2. Cultura universitaria: Gestión por resultados, buena gobernanza, excelencia investigadora y docente, programas de investigación conjunta y contractual.

3. Competencias y capacidades del profesorado/facultad: Ranking administrativo y académico del profesorado/facultad, investigadoras, evaluación del rendimiento de investigadores y docentes.

4. Instalaciones/infraestructura: Apoyo a la investigación y la docencia, evaluación de calidad de las instalaciones e infraestructura. 
Por otro lado, a través de la gestión adecuada y la vinculación a la demanda de ES (sociedad), la ES puede suministrar eficientemente resultados (profesionales e investigación), vinculados eficazmente a la demanda de ES. En otras palabras, que los demandantes tengan la mejor percepción del valor (eficacia) de dichos resultados, suministrados con el menor gasto (optimización). Para ello, se debe operativizar la cadena de valor en ambas cadenas de suministro de la ES. Finalmente, es necesario considerar simultáneamente en el desarrollo y evaluación de docencia e investigación vinculadas a la demanda de ES, tres niveles de decisión: estratégicos, tácticos (de planificación) y operativos (Fig. 9) (Habib, 2011).

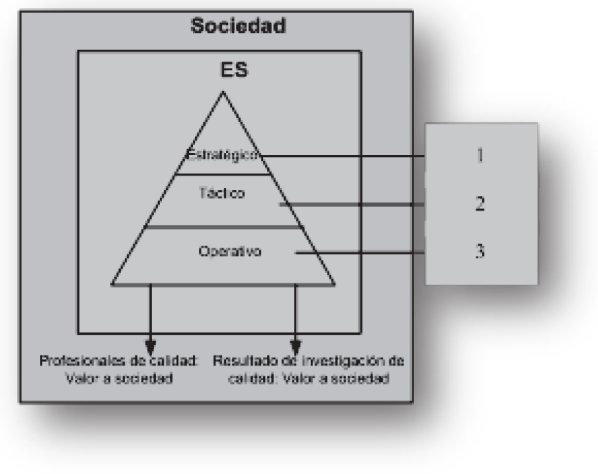

$\mathbf{E} \& \mathbf{A}$

Figura 9.

Decisiones en un sistema de valor y de suministro

(Habib, 2011)

Nivel 1. Estratégico. La estrategia en las organizaciones trasciende no sólo el sector de manufactura (ej. Ortega Jiménez et al, 2011; Machuca et al., 2011; Ortega et al., 2012), sino también el de servicios como la educación superior (Habib, 2011). Las estrategias para suministrar eficientemente profesionales y resultados de investigación vinculados a la demanda de ES de manera eficaz (mejor valor percibido por el demandante), se deben formular en el desarrollo y evaluación de docencia y de investigación conforme los elementos de la Figura 10, presentados a continuación (Habib, 2011). Profesionales vinculados a la demanda de ES: Para su suministro, se deben identificar determinantes de benchmarking y de mejora de valor e incorporarlos en el proceso de ES: 
a) Benchmarking de profesionales

- Conocimiento (tácito y explicito)

- Habilidades/destrezas

- Competencias

- Ética

- Programas de desarrollo de carreras

b) Mejora de valor de profesionales

- $\quad$ Fuente de fondos (autofinanciamiento, beca, familia, trabajo, etc.)

- Conocimiento

- Capacidades y competencias

- Instalaciones

- Infraestructura (TIC, laboratorios, etc.)

- Involucramiento en investigación

- Resultados de investigación vinculados a la demanda de ES: En el nivel estratégico, la ES desarrolla planes para investigaciones especializadas, interdisciplinarias y multidisciplinarias para mantener un énfasis en investigación como un componente importante de la misión académica de la ES. Los resultados de investigación pueden incluir, entre otros:

a. Solución de problemas

b. Resultados de tesis

c. Teoría fundamental

d. Aplicaciones de proyectos internos y externos

e. Publicaciones y congresos/conferencias de investigación

f. Resultados de investigación

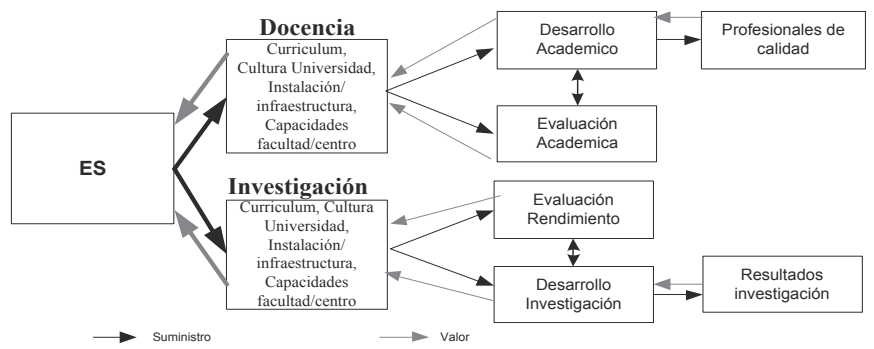

Figura 10.

Nivel interno de estrategia del SIVSES

(Adaptado de Habib, 2011) 
Nivel 2. Táctico. Se desarrollan planes de ambas cadenas de suministro de la oferta, docencia e investigación, así como planes de evaluación de vinculación a la demanda de ES, por medio del valor percibido por los demandantes de profesionales y resultados de investigación, midiendo el valor agregado en todo el proceso de ambas cadenas de suministro. Así pues, para el desarrollo y evaluación se planifican cuatros elementos en la Figura 11, a saber: desarrollo curricular, instalaciones/ infraestructura, cultura universitaria y capacidades/competencias de facultad/profesorado) (Habib y Jungthirapanich, 2010).

1. Desarrollo curricular
a. Libros de texto
b. Contenidos de cursos acreditados
c. Documentos de cátedras
d. TIC
e. Seminarios
f. Proyectos

2. Instalaciones/Infraestructura
a. Aulas de clase
b. Internet
c. Laboratorios
d. TIC
e. Base de datos en línea y revistas internacionales

3. Cultura universitaria
a. Forma de Gobierno/Gestión y Administración
b. Autoevaluación y acreditación
c. Leyes, Reglamentos, Regulaciones, Políticas
d. Ética, Disciplina y Conducta
e. Unidades de apoyo (admón. finanzas, actividades universitarias, etc.)
f. Coordinación con otras universidades e industrias
g. Ex alumnos
h. Proyectos de investigación
i. Centros de investigación 
4. Capacidad y competencias de facultad (unidad): Evaluación del rendimiento, que contempla:

a. Planes de evaluación de vinculación a demanda de ES (valores percibidos y agregados) de docencia

b. Planes de evaluación de rendimiento de investigación de ES (valores percibidos y agregados).

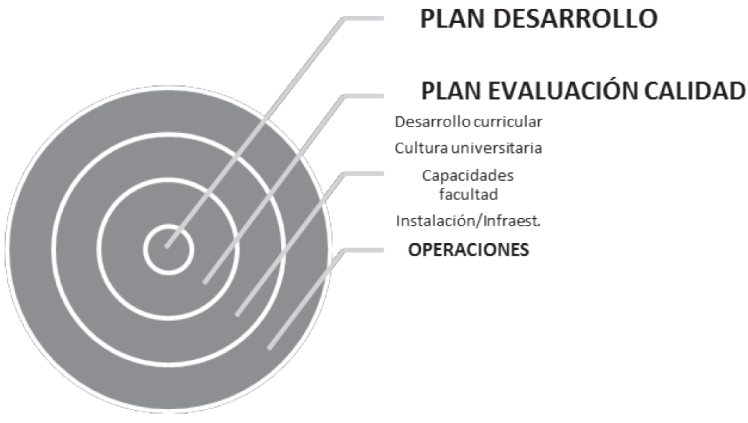

Figura 11.

\section{Nivel interno de planificación del SIVSES: docencia e investigación}

(Adaptado de Habib y Jungthirapanich, 2010)

Nivel 3. Operativo. Se realizan operaciones de docencia, rendimiento de investigación, evaluaciones de vinculación por medio del valor percibido por los demandantes, de profesionales y de rendimientos de investigación, verificando el valor agregado por las cadenas de suministro respectivas en cada parte del proceso de ES. En la Figura 12, se puede ver que la investigación de ES (resaltado de forma más oscura) necesita (se circunscribe) de la docencia para operar en la ES. Los elementos a considerar son los siguientes (Habib y Jungthirapanich, 2010):

1. Estudiantes que ingresan a la universidad, se les agrega valor para convertirse en profesionales de ES, de acuerdo a la de demanda de ES.

2. Proyectos de investigación que se preparan y programan para un proceso que agrega valor, concluyendo en resultados de investigación de calidad, según demanda de ES.

3. Rendimiento general: Sistema de medida del rendimiento, indicadores de rendimiento de investigación y de docencia, encuesta de empleadores/demandantes y empleados/proyectos. 


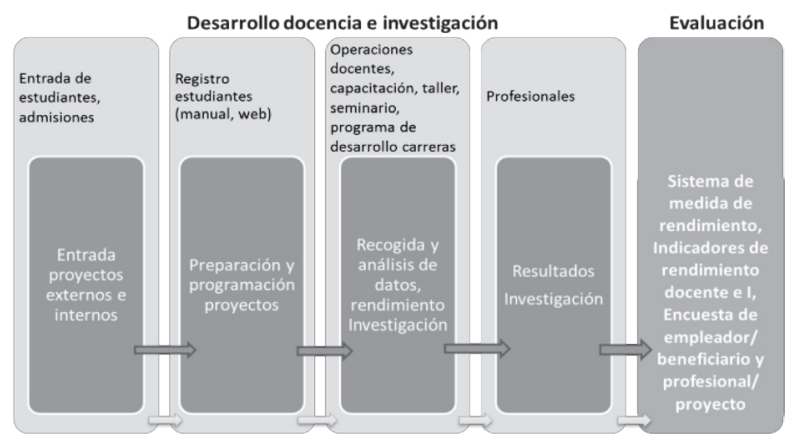

Figura 12.

Nivel interno de operaciones del SIVSES

(Adaptado de Habib y Jungthirapanich, 2010)

En relación a los indicadores del rendimiento del SIVSES, una medida conjunta de la cadena de valor y de suministro es en términos de eficacia y eficiencia, respectivamente (Figura 13). La eficacia mide el valor por la extensión en el que los resultados han sido alcanzados y la eficiencia mide los gastos/falta de calidad del suministro por los recursos usados para lograr cierto nivel de resultado. El rendimiento de la ES depende de la calidad de los profesionales y de los resultados de investigación. De la misma manera, el rendimiento de la cadena de valor y de suministro integrada depende del rendimiento de la ES. Para lograr mayor rendimiento en la cadena, se debe asegurar el mejor rendimiento de la ES basado en la satisfacción de los demandantes, así como todos los actores. El rendimiento general se puede medir por un sistema de medición de rendimiento, indicadores de rendimiento docente y de investigación y encuestas de empleadores/beneficiarios y empleados/proyectos finalizados.

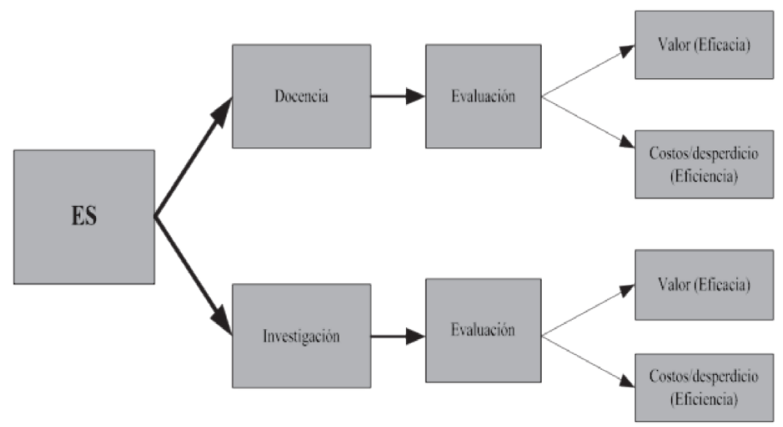

Figura 13.

\section{Rendimiento del SIVSES}

(Adaptado de Habib y Jungthirapanich, 2010) 
Tomando lo anterior, se puede llegar a un modelo de gestión integrado, que articula todos los elementos anteriores. La Figura 14 muestra que por medio de la gestión adecuada y la vinculación a la demanda, la ES puede suministrar resultados vinculados eficazmente a la demanda (sociedad).

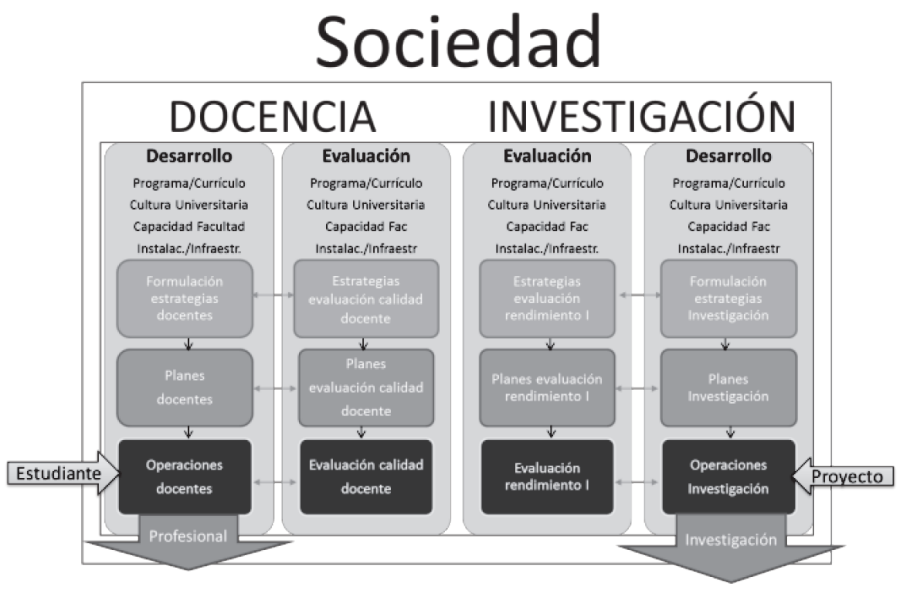

Figura 14.

Articulación del SIVSES

(Adaptado Habib y Jungthirapanich, 2010)

Así pues, aunque la ES puede proveer productos (ej. PI), la gestión de ES se considera primordialmente como un proveedor de servicios. Para ello, la Figura 14 identifica las dos partes principales de la ES: desarrollo y evaluación, no sólo para la docencia sino también para la investigación. La gestión debe incluir los tres niveles de decisión (Estratégico, Táctico y Operativo), tanto para la docencia como para la investigación de la ES. Como resultado final, se busca entregar a los demandantes, profesionales y resultados de investigación vinculados a la demanda de ES (eficacia) por la cadena de valor. Ello presenta un apoyo significativo a la Proposición 1.

Por otro lado, a continuación las Tablas 2 y 3 muestran los elementos específicos del desarrollo y evaluación de docencia de ES respectivamente, y las Tablas 4 y 5 los elementos específicos del desarrollo y evaluación de investigación de ES respectivamente (Habib y Jungthirapanich, 2010). 
Tabla No 2.

Desarrollo de docencia de ES vinculada a la demanda de ES

(Adaptado de Habib y Jungthirapanich, 2010)

\begin{tabular}{|c|c|c|c|c|}
\hline $\begin{array}{l}\text { Niveles } \\
\text { Decisión }\end{array}$ & $\begin{array}{c}\text { Establecimiento } \\
\text { Programas } \\
\text { vinculados a la } \\
\text { demanda de ES }\end{array}$ & $\begin{array}{c}\text { Cultura de } \\
\text { Universidad según } \\
\text { demanda de } \mathrm{ES}\end{array}$ & $\begin{array}{l}\text { Capacidades/ } \\
\text { competencias de } \\
\text { Facultad según } \\
\text { demanda de ES } \\
\end{array}$ & $\begin{array}{c}\text { Instalaciones/ } \\
\text { Infraestructura según } \\
\text { demanda de ES }\end{array}$ \\
\hline Estratégico & $\begin{array}{l}\text { F./E. Ingeniería, } \\
\text { F. Ciencias } \\
\text { Económicas, } \\
\text { F. Ciencias } \\
\text { Sociales, etc., } \\
\text { según sociedad }\end{array}$ & $\begin{array}{l}\text { Académico, Buena } \\
\text { gobernabilidad por } \\
\text { autoridad Universitaria } \\
\text { vinculado a sociedad }\end{array}$ & $\begin{array}{l}\text { Profesor vinculado } \\
\text { a sociedad }\end{array}$ & $\begin{array}{l}\text { Como apoyo y docencia } \\
\text { de la } \\
\text { Universidad vinculado } \\
\text { a sociedad }\end{array}$ \\
\hline Táctico & $\begin{array}{l}\text { Departamento de } \\
\text { Eléctrica, } \\
\text { Departamento } \\
\text { de Economía, } \\
\text { Sociología, etc., } \\
\text { según sociedad }\end{array}$ & $\begin{array}{l}\text { Académico, } \\
\text { Buena } \\
\text { gobernabilidad } \\
\text { por Decano/ } \\
\text { Jefe de Depto./ } \\
\text { Carrera } \\
\text { vinculado a } \\
\text { sociedad } \\
\end{array}$ & $\begin{array}{l}\text { Profesor vinculado } \\
\text { a sociedad }\end{array}$ & $\begin{array}{l}\text { Como apoyo y docencia } \\
\text { de la Facultad/Escuela } \\
\text { vinculado a sociedad }\end{array}$ \\
\hline Operativo & $\begin{array}{l}\text { Áreas de } \\
\text { conocimiento/ } \\
\text { concentración/ } \\
\text { especialidad } \\
\text { conforme } \\
\text { demanda de ES }\end{array}$ & $\begin{array}{l}\text { Académico, Buena } \\
\text { gobernabilidad } \\
\text { por miembros de } \\
\text { facultad vinculado } \\
\text { a sociedad }\end{array}$ & $\begin{array}{l}\text { Profesor vinculado } \\
\text { a sociedad }\end{array}$ & $\begin{array}{l}\text { Como apoyo } \\
\text { y docencia del } \\
\text { Departamento/ } \\
\text { unidad vinculado a } \\
\text { sociedad }\end{array}$ \\
\hline
\end{tabular}

E\&A

Tabla No 3.

Evaluación de docencia de ES vinculada a la demanda de ES

(Adaptado de Habib y Jungthirapanich, 2010)

\begin{tabular}{|l|l|l|l|l|}
\hline $\begin{array}{c}\text { Niveles } \\
\text { Decisión }\end{array}$ & $\begin{array}{c}\text { Establecimiento } \\
\text { Programas } \\
\text { vinculados a la } \\
\text { demanda de ES }\end{array}$ & $\begin{array}{c}\text { Cultura de } \\
\text { Universidad según } \\
\text { demanda de ES }\end{array}$ & $\begin{array}{l}\text { Capacidades/ } \\
\text { competencias de } \\
\text { Facultad según } \\
\text { demanda de ES }\end{array}$ & $\begin{array}{c}\text { Instalaciones/ } \\
\text { Infraestructura } \\
\text { según demanda } \\
\text { de ES }\end{array}$ \\
\hline Estratégico & $\begin{array}{l}\text { Programa de } \\
\text { garantía académica } \\
\text { de Universidad } \\
\text { conforme demanda } \\
\text { de ES }\end{array}$ & $\begin{array}{l}\text { Gestión por } \\
\text { resultados, } \\
\text { Excelencia } \\
\text { académica } \\
\text { universitaria } \\
\text { considerando valor } \\
\text { percibido }\end{array}$ & $\begin{array}{l}\text { Evaluación del } \\
\text { rendimiento } \\
\text { del docente de } \\
\text { universidad } \\
\text { considerando valor } \\
\text { percibido }\end{array}$ & $\begin{array}{l}\text { Como apoyo } \\
\text { y docencia de } \\
\text { la calidad de } \\
\text { universidad de } \\
\text { considerando valor } \\
\text { percibido }\end{array}$ \\
\hline
\end{tabular}




\begin{tabular}{|l|l|l|l|l|}
\hline $\begin{array}{c}\text { Niveles } \\
\text { Decisión }\end{array}$ & $\begin{array}{c}\text { Establecimiento } \\
\text { Programas } \\
\text { vinculados a la } \\
\text { demanda de ES }\end{array}$ & $\begin{array}{l}\text { Cultura de } \\
\text { Universidad según } \\
\text { demanda de ES }\end{array}$ & $\begin{array}{c}\text { Capacidades/ } \\
\text { competencias de } \\
\text { Facultad según } \\
\text { demanda de ES }\end{array}$ & $\begin{array}{c}\text { Instalaciones/ } \\
\text { Infraestructura } \\
\text { según demanda } \\
\text { de ES }\end{array}$ \\
\hline Táctico & $\begin{array}{l}\text { Programa de } \\
\text { garantía académica } \\
\text { de Facultad/Escuela } \\
\text { conforme demanda } \\
\text { de ES }\end{array}$ & $\begin{array}{l}\text { Excelencia } \\
\text { académica } \\
\text { considerando valor } \\
\text { percibido }\end{array}$ & $\begin{array}{l}\text { Evaluación del } \\
\text { rendimiento docente } \\
\text { de facultad/escuela } \\
\text { considerando valor } \\
\text { percibido }\end{array}$ & $\begin{array}{l}\text { Como apoyo } \\
\text { y docencia de } \\
\text { evaluación de la } \\
\text { calidad de facultad } \\
\text { considerando valor } \\
\text { percibido }\end{array}$ \\
\hline Operativo & $\begin{array}{l}\text { Programa de } \\
\text { garantía académica } \\
\text { de depto./carrera } \\
\text { conforme demanda } \\
\text { de ES }\end{array}$ & $\begin{array}{l}\text { Excelencia } \\
\text { académica } \\
\text { considerando valor } \\
\text { percibido }\end{array}$ & $\begin{array}{l}\text { Evaluación del } \\
\text { rendimiento docente } \\
\text { de depto./carrera } \\
\text { considerando valor } \\
\text { percibido }\end{array}$ & $\begin{array}{l}\text { Como apoyo } \\
\text { ydocencia de } \\
\text { evaluación de } \\
\text { la calidad del } \\
\text { departamento } \\
\text { considerando valor } \\
\text { percibido }\end{array}$ \\
\hline
\end{tabular}

E\&A

Tabla No 4.

Desarrollo de investigación de ES vinculada a la demanda de ES

(Adaptado de Habib y Jungthirapanich, 2010)

\begin{tabular}{|c|c|c|c|c|}
\hline $\begin{array}{l}\text { Niveles } \\
\text { Decisión }\end{array}$ & $\begin{array}{l}\text { Establecimiento } \\
\text { Programas } \\
\text { vinculados a la } \\
\text { demanda de ES }\end{array}$ & $\begin{array}{l}\text { Cultura de Universidad } \\
\text { según demanda de ES }\end{array}$ & $\begin{array}{l}\text { Capacidades/ } \\
\text { competencias de } \\
\text { Facultad según } \\
\text { demanda de ES } \\
\end{array}$ & $\begin{array}{c}\text { Instalaciones/ } \\
\text { Infraestructura según } \\
\text { demanda de ES }\end{array}$ \\
\hline Estratégico & $\begin{array}{l}\text { Programas de } \\
\text { investigación de } \\
\text { facultad/escuela } \\
\text { según sociedad }\end{array}$ & $\begin{array}{l}\text { Orientación de } \\
\text { investigación de } \\
\text { universidad vinculado a } \\
\text { sociedad }\end{array}$ & $\begin{array}{l}\text { profesores, } \\
\text { investigadores } \\
\text { vinculado a } \\
\text { sociedad }\end{array}$ & $\begin{array}{l}\text { Como apoyo e investigación } \\
\text { de la } \\
\text { Universidad vinculado a } \\
\text { sociedad }\end{array}$ \\
\hline Táctico & $\begin{array}{l}\text { Proyectos de } \\
\text { investigación de } \\
\text { Facultad según } \\
\text { sociedad }\end{array}$ & $\begin{array}{l}\text { Programas de } \\
\text { investigación } \\
\text { contractuales } \\
\text { de facultad y } \\
\text { programas de } \\
\text { investigación } \\
\text { conjuntos } \\
\text { vinculado a } \\
\text { sociedad }\end{array}$ & $\begin{array}{l}\text { profesores, } \\
\text { investigadores } \\
\text { vinculado a } \\
\text { sociedad }\end{array}$ & $\begin{array}{l}\text { Como apoyo e investigación } \\
\text { de facultad vinculado a } \\
\text { sociedad }\end{array}$ \\
\hline Operativo & $\begin{array}{l}\text { Temáticas de } \\
\text { investigación de } \\
\text { unidades conforme } \\
\text { demanda de ES }\end{array}$ & $\begin{array}{l}\text { Proyectos de } \\
\text { investigación } \\
\text { innovadores por depto. } \\
\text { vinculado a sociedad }\end{array}$ & $\begin{array}{l}\text { profesores, } \\
\text { investigadores } \\
\text { vinculado a } \\
\text { sociedad }\end{array}$ & $\begin{array}{l}\text { De apoyo y de investigación } \\
\text { de departamento vinculado a } \\
\text { sociedad }\end{array}$ \\
\hline
\end{tabular}


Tabla No 5.

Evaluación de investigación de ES vinculada a la demanda de ES

(Adaptado de Habib y Jungthirapanich, 2010)

\begin{tabular}{|c|c|c|c|c|}
\hline $\begin{array}{l}\text { Niveles } \\
\text { Decisión }\end{array}$ & $\begin{array}{c}\text { Establecimiento } \\
\text { Programas vinculados a } \\
\text { la demanda de ES }\end{array}$ & $\begin{array}{c}\text { Cultura de } \\
\text { Universidad según } \\
\text { demanda de ES } \\
\end{array}$ & $\begin{array}{c}\text { Capacidades/competencias } \\
\text { de Facultad según } \\
\text { demanda de ES }\end{array}$ & $\begin{array}{c}\text { Instalaciones/ } \\
\text { Infraestructura según } \\
\text { demanda de ES }\end{array}$ \\
\hline Estratégico & $\begin{array}{l}\text { Programa de garantía de } \\
\text { investigación vinculada } \\
\text { a demanda de ES en } \\
\text { Universidad }\end{array}$ & $\begin{array}{l}\text { Evaluación de } \\
\text { resultados de } \\
\text { investigación } \\
\text { vinculados a } \\
\text { demanda de ES en } \\
\text { Universidad. } \\
\text { Excelencia de } \\
\text { investigación } \\
\text { universitaria. } \\
\text { Considerando valor } \\
\text { percibido }\end{array}$ & $\begin{array}{l}\text { Evaluación del } \\
\text { rendimiento investigativo } \\
\text { de universidad, } \\
\text { considerando valor } \\
\text { percibido }\end{array}$ & $\begin{array}{l}\text { Como apoyo e } \\
\text { investigación } \\
\text { de evaluación } \\
\text { de la } \\
\text { calidad de } \\
\text { Universidad, } \\
\text { considerando } \\
\text { valor percibido }\end{array}$ \\
\hline Táctico & $\begin{array}{l}\text { Programa de } \\
\text { garantía de } \\
\text { investigación } \\
\text { vinculada a } \\
\text { demanda de ES en } \\
\text { Facultad }\end{array}$ & $\begin{array}{l}\text { Evaluación } \\
\text { del entorno de } \\
\text { investigación } \\
\text { en Facultad, } \\
\text { considerando valor } \\
\text { percibido }\end{array}$ & $\begin{array}{l}\text { Evaluación del } \\
\text { rendimiento } \\
\text { investigativo de } \\
\text { facultad, considerando } \\
\text { valor percibido }\end{array}$ & $\begin{array}{l}\text { Como apoyo e } \\
\text { investigación } \\
\text { de evaluación } \\
\text { de la calidad } \\
\text { de facultad, } \\
\text { considerando } \\
\text { valor percibido }\end{array}$ \\
\hline Operativo & $\begin{array}{l}\text { Programa de } \\
\text { garantía de } \\
\text { investigación } \\
\text { vinculada a } \\
\text { demanda de ES en } \\
\text { Departamento }\end{array}$ & $\begin{array}{l}\text { Excelencia de } \\
\text { investigación en } \\
1 \text { departamento, } \\
\text { considerando valor } \\
\text { percibido }\end{array}$ & $\begin{array}{l}\text { Evaluación del } \\
\text { rendimiento } \\
\text { investigativo de } \\
\text { departamento, } \\
\text { considerando valor } \\
\text { percibido }\end{array}$ & $\begin{array}{l}\text { Como apoyo e } \\
\text { investigación } \\
\text { de evaluación } \\
\text { de la calidad de } \\
\text { departamento, } \\
\text { considerando valor } \\
\text { percibido }\end{array}$ \\
\hline
\end{tabular}

\section{GESTIÓN DE OPERACIONES: RELACIONES ENTRE LAS CADENAS}

Considerando los elementos a través del presente estudio, la Figura 15 muestra todos los actores de la oferta y demanda de ES y las relaciones que deben existir en la gestión de operaciones del modelo del SIVSES, con su dos cadenas de suministro (docencia e investigación) (Habib y Jungthirapanich, 2010) y su cadena de valor (Porter, 1985) de vinculación a la demanda de ES. En la Figura se puede ver que la cadena de valor realimenta ambas cadenas de suministro, dando apoyo a la Proposición 2. 


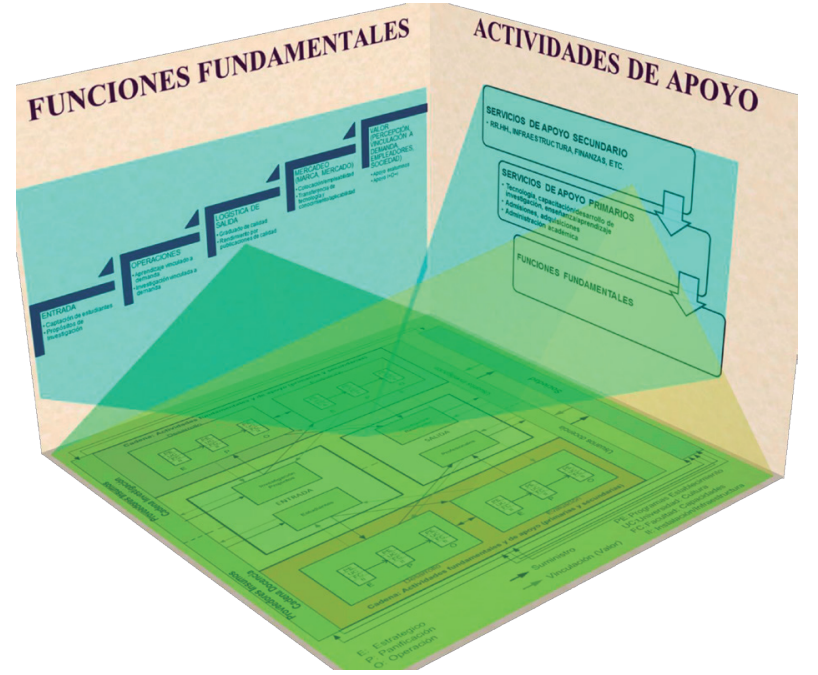

Figura 15.

Gestión del SIVSES: actores, relaciones, cadenas, actividades y partes

(Adaptado de Ortega y Eguía, 2011; Habib y Jungthirapanich, 2010; Pathak y Pathak, 2010; Porter, 1985;)

Finalmente, en el proceso de operaciones del modelo del SIVSES pueden existir tres casos de la oferta de ES suplida en relación a la demanda de ES:1) una sobreoferta de ES, 2) una adecuación entre la oferta y la demanda esperada, y 3) una baja oferta de ES. Así pues, para lograr un balance oferta-demanda, el flujo bidireccional sistematizado de información entre demandantes y ofertantes de ES es clave en la eficiencia y eficacia de los resultados que las IES's necesitan entregar a la sociedad. Para ello, de la medición de las interconexiones entre los actores, procesos, insumos y resultados del SIVSES en la Figura 15, se manifiestan tres tipos de relaciones entre el ofertante (IES) y el demandante (empleador y usuarios de resultados de ES), que pueden existir en cualquiera de los tres casos de la oferta suministrada ${ }^{15}$. La mejora continua del SIVSES debe ser la búsqueda de una relación directa, que es el primero de las tres conexiones ofertante-demandante que se explican a continuación:

- Relación directa. Es una interconexión con un flujo bidireccional entre demandante y ofertante, que permite el intercambio de información, realimentando la demanda esperada. Ello posibilita hacer las correcciones a la oferta (de ser necesarias)

$\diamond$ Conexión directa entre programas de disciplinas y puestos de trabajo: docencia por competencias, carreras, grados, etc.

15 De manera similar se puede establecer la relación entre proveedores de insumos de ES y ofertantes de ES. 
$\diamond \quad$ Conexión directa entre programas de investigación y necesidades de desarrollo e innovación: investigación por proyectos de $\mathrm{I}+\mathrm{D}+\mathrm{i}$, etc.

- Relación limitada. Existe alguna conexión, posiblemente un flujo unidireccional entre demandante y ofertante. Al no existir relaciones directas no permite hacer correcciones en la oferta de ES.

$\diamond \quad$ Un flujo de la IES a la sociedad (empleador y usuario de proyecto). Es posiblemente el más común, donde la IES presenta su oferta educativa sin considerar las necesidades de la sociedad, ni que el empleador realimente sus requerimientos.

$\diamond \quad$ Un flujo de la sociedad a la IES. Es el menos común de los dos tipos de flujos unidireccionales. En este caso, la IES no reacciona a la información que recibe de la sociedad.

- Relación débil. Es una conexión pobre, sin ningún flujo de información.

Tomando todos los elementos considerados en la gestión de operaciones del SIVSES (Figura 15), se pueden establecer las siguientes relaciones, que presentan un apoyo significativo a la Proposición 2:

1. Proveedores de insumos de docencia-ES

a. Existe una relación entre los proveedores de insumos de docencia y universidades.

b. Se vinculan (sistematizan una articulación) las universidades con proveedores de insumos de docencia

c. Existe una relación entre los proveedores de insumos de docencia y estudiantes en las universidades.

2. Proveedores de insumos de investigación-ES

a. Una relación entre los proveedores de insumos de investigación y universidades.

b. Se vinculan las universidades con proveedores de insumos de investigación

c. Existe una relación entre los proveedores de insumos de investigación y proyectos de investigación en las universidades.

3. Estudiantes de ES-demandantes de profesionales

a. Existe una relación entre estudiantes y demandantes de profesionales.

b. Vinculan/articulan las universidades a los estudiantes y demandantes de profesionales.

4. Investigación de ES-demandantes de investigación

a. Existe una relación entre resultados de investigación y demandantes de investigación.

b. Vinculan las universidades sus resultados de investigación con los demandantes de investigación (fricciones del mercado). 
5. Demandantes intermedios de profesionales-sociedad

a. Existe una relación entre profesionales y sociedad (empleadores) (fricciones del mercado).

b. Existe una relación entre colegios profesionales y sociedad.

c. Existe una relación entre estudiantes (o graduados) y colegios profesionales.

d. Existe una relación entre cooperantes de docencia de ES y la sociedad (empleadores

e. Vinculan las universidades a los profesionales y la sociedad (empleadores).

6. Demandantes intermedios de investigación-sociedad

a. Existe una relación entre demandantes intermedios de investigación y la sociedad.

b. Existe una relación entre cooperantes de investigación de ES y la sociedad (empleadores).

c. Vinculan las universidades a los demandantes intermedios de investigación y la sociedad.

7. Desarrollo de docencia-profesionales

a. Existe una relación entre desarrollo de docencia y profesionales

b. Cuatro factores influyen el desarrollo de docencia en las universidades para producir profesionales

i. El establecimiento de programas afecta significativamente el desarrollo de docencia a los tres niveles (estrategia, planificación y operaciones).

ii. La cultura de universidad afecta significativamente el desarrollo de docencia a los tres niveles.

iii. Las capacidades de facultad afectan significativamente el desarrollo de docencia a los tres niveles.

iv. Las instalaciones/infraestructura afectan significativamente el desarrollo de docencia a los tres niveles.

8. Existe una relación entre evaluación de docencia y profesionales

a. Cuatro factores influyen la evaluación de docencia en las universidades para producir profesionales

i. El establecimiento de programas afecta significativamente la evaluación de docencia a los tres niveles (Estratégico, Táctico y Operativo).

ii. La cultura de universidad afecta significativamente la evaluación de docencia a los tres niveles.

iii. Las capacidades de facultad afectan significativamente la evaluación de docencia a los tres niveles. 
iv. Las instalaciones/infraestructura afectan significativamente la evaluación de docencia a los tres niveles.

9. Existe una relación entre desarrollo de investigación y resultados de investigación

a. Cuatro factores influyen el desarrollo de investigación en las universidades para realizar investigaciones

i. El establecimiento de programas afecta significativamente el desarrollo de investigación a los tres niveles (estrategia, planificación y operaciones).

ii. La cultura de universidad afecta significativamente el desarrollo de investigación a los tres niveles.

iii. Las capacidades de facultad afectan significativamente el desarrollo de investigación a los tres niveles.

iv. Las instalaciones/infraestructura afectan significativamente el desarrollo de docencia a los tres niveles.

10. Existe una relación entre evaluación de investigación y resultados de investigación

a. Cuatro factores influyen la evaluación de investigación en las universidades para realizar investigaciones

i. El establecimiento de programas afecta significativamente la evaluación de docencia a los tres niveles (estrategia, táctica y operaciones).

ii. La cultura de universidad afecta significativamente la evaluación de docencia a los tres niveles.

iii. Las capacidades de facultad afectan significativamente la evaluación de docencia a los tres niveles.

iv. Las instalaciones/infraestructura afectan significativamente la evaluación de docencia a los tres niveles.

11. Se vinculan las universidades por medio de mejorar la percepción del valor de los resultados que entregan en docencia y en investigación (mercadeo, innovación y un proceso con relaciones que añaden valor).

12. Existe una ES eficaz que busca el mayor beneficio de los demandantes de ES, con valores agregados en todo el proceso, desde los insumos, ES (actividades fundamentales y de apoyo primarias y secundarias) y beneficiarios en las dos cadenas de valor, docencia e investigación. 
13. El proceso de la cadena de suministro de docencia es eficiente, desde los insumos, ES (actividades fundamentales y de apoyo primarias y secundarias) y beneficiarios, evitando el desperdicio y entregando lo que valoran los beneficiarios

14. El proceso de la cadena de suministro de investigación es eficiente, desde los insumos, ES (actividades fundamentales y de apoyo primarias y secundarias) y beneficiarios, evitando el desperdicio y entregando lo que valoran los beneficiarios

15. Existe un margen entre el valor percibido y el costo (menor desperdicio) de entrega de graduados, productos y servicios, que es mayor para las universidades de mayor rendimiento

16. Existen relaciones entre las funciones y actividades fundamentales de ES (entrada, operaciones, logística de salida, mercadeo y servicio) y las de apoyo (primarias y secundarias).

17. Existe una sobreoferta que se muestra de una de las siguientes tres maneras

a. Sobreoferta categórica de profesionales y/o proyectos respecto a la demanda esperada en una relación directa ofertante-demandante. Ello puede sugerir reducir inversiones en los programas sobre ofertados.

b. Sobreoferta supuesta de profesionales y/o proyectos respecto a la demanda esperada en una relación limitada ofertante-demandante. Ello puede significar competencia intensa por oportunidades limitadas a usar resultados de ES. Antes de hacer inversiones en programas se requiere identificar vínculos de mercados especiales mejorando la relación limitada.

c. Sobreoferta probable de profesionales y/o proyectos respecto a la demanda esperada en una relación débil ofertante-demandante. La pobre conexión con la demanda anula el análisis de datos de oferta y demanda. Dichos programas sobre ofertados deben ser revisados o cancelados.

18. Existe una adecuación/balance oferta-demanda que se muestra de una de las siguientes tres formas:

a. Oferta balanceada categórica de profesionales y/o proyectos respecto a la demanda esperada en una relación directa ofertante-demandante. Aunque la competencia por profesionales y/o proyectos es muy competitiva, hay oportunidades para usar resultados de ES.

b. Oferta balanceada supuesta de profesionales y/o proyectos respecto a la demanda esperada en una relación limitada ofertante-demandante. Los datos no determinan una situación de superávit o de carencia de resultados de ES. Es necesaria mayor revisión de dichos programas 
para determinar si hay mayores oportunidades de usar resultados de ES debido a puestos de trabajo y/o necesidades de proyectos.

c. Oferta balanceada probable de profesionales y/o proyectos respecto a la demanda esperada en una relación débil ofertante-demandante. La pobre conexión con la demanda anula el análisis de datos de oferta y demanda. Se necesita revisión de la conexión ofertante-demandante para determinar posibles oportunidades de mercado de profesionales y proyectos.

19. Existe una baja oferta que se muestra de una de las siguientes tres formas:

a. Baja demanda categórica de profesionales y/o proyectos respecto a la demanda esperada en una relación directa ofertante-demandante. Los datos indican posibles carencias de resultados de investigación. Posiblemente se necesitan recursos adicionales y esfuerzos concentrados de captación de insumos en los programas de baja oferta para aumentarlos.

b. Baja demanda supuesta de profesionales y/o proyectos respecto a la demanda esperada en una relación limitada ofertante-demandante. Las oportunidades de mercado para resultados de ES probablemente existen. Se necesita determinar mayores conexiones entre ofertante y demandante.

c. Baja demanda probable de profesionales y/o proyectos respecto a la demanda esperada en una relación débil ofertante-demandante. La pobre conexión con la demanda anula el análisis de datos de oferta y demanda. Puede existir demanda de resultados de ES pero no necesariamente conectados directamente a estos programas de bajo demanda Se necesita revisión de la posible articulación demandante-ofertante para determinar oportunidades de mercado de profesionales y proyectos.

20. Existen deficiencias de insumos de la cadena de docencia en el SIVSES de las siguientes formas:

a. Graduados de EM con las cualificaciones requeridas para estudiar ES que no entran en la ES.

b. Graduados de EM que entran en la ES sin tener las cualificaciones requeridas.

c. Estudiantes de ES que estudian y trabajan.

d. Estudiantes de ES que han dejado de estudiar.

e. Estudiantes de ES que han vuelto a estudiar después de haberlo abandonado por más de un año.

f. No hay una cadena de valor conectada a la cadena de suministro. 
21. Existen deficiencias de insumos en la cadena de investigación del SIVSES de las siguientes formas:

a. Consultorías y/o investigaciones que los sectores públicos, y/o privados, y/o sin fines de lucro no hacen en conjunto con la academia.

b. Consultorías y/o investigaciones que se hacen en la academia después de haber sido iniciadas en otro sector (ej. privado, público, etc.), que debió empezar en la academia desde su inicio.

c. No hay una cadena de valor conectada a la cadena de suministro.

22. Existen relaciones entre el SIVSES o sus elementos y su contexto

a. Desarrollo y crecimiento económico (ej. producto interno bruto, creación de riqueza, mejora de la calidad de vida, etc.).

b. Investigación con impacto en el desarrollo e innovación.

\section{CONCLUSIONES}

Hasta ahora la literatura presenta un marco conceptual de ambas cadenas de suministros (docencia e investigación). En relación a la cadena de valor (vinculación a demanda de ES) sólo hay algunos intentos de fundamentos generales en la propuesta del SIVSES de Ortega y Eguía (2011). Sin embargo, a la fecha no se ha presentado un marco de referencias que permita operar los componentes de ambos tipos de cadenas (suministro y valor) para lograr resultados vinculados a la demanda de ES: profesionales graduados y resultados de investigación, guiados por la demanda de ES (principalmente la sociedad).

Así pues, el presente estudio provee una gestión de operaciones innovadora que desarrolla y evalúa las cadenas del enfoque del SIVSES, con el objeto de la búsqueda de un mejor balance entre la oferta y demanda de la ES. Esta investigación representa el fundamento conceptual para el estudio empírico que se está realizando actualmente, donde se propone probar dicho planteamiento de gestión de operaciones a través de la recolección y análisis de una gran cantidad de información de datos primarios y secundarios por medio de una batería de cuestionarios dirigidos a proveedores de insumos de ES, ofertantes de ES y demandantes de ES. 
Por lo tanto, proponer una operativización del SIVSES, significa ir más allá del modelo actual del pilar de cadenas de suministro por Habib, al añadir otros cuatro pilares, dejando cinco pilares en total: 1) las dos cadenas de suministro (investigación y docencia) de Habib; 2) la cadena de valor (Porter, 1985), en paralelo y en sentido opuesto por medio de la vinculación a la demanda de ES; 3) otros resultados (ej. hacia la ES (profesores, personal administrativo y técnico, investigaciones, etc.), hacia la EM (profesores, personal administrativo y técnico, investigaciones, etc.); 4) las fricciones del mercado de profesionales e investigaciones de ES; y 5) la fricciones del SIVSES en sí.

Finalmente, como investigación futura del modelo, es importante considerar algunos métodos de análisis en el estudio empírico en curso, tales como una lista de comprobación (check list) de gastos de entrega para la ES, métodos de análisis causal (ej. interpretar la interrelaciones entre variables con un diagrama de Ishikawa), una EDT (Estructura de División del Trabajo) para la gestión del SIVSES, etc., que contribuyan a las posibles limitaciones teóricas del modelo de gestión de operaciones.

\section{Reconocimientos}

Esta investigación ha sido financiada parcialmente por el Consejo Nacional de Educación la Vicerrectoría Académica de la UNAH, y los becarios de la beca 003-2009-UNAH. Los autores desean agradecer el apoyo del Gobierno de Honduras, de la UNAH, y de los becarios.

\section{REFERENCIAS}

Abrahamson, E. y Farichild G, 1999. Management Fashion: Lifecycles, Triggers, and Collective Learning Processes. Administrative Science Quarterly 44 (4), 708-40.

Feller, A., Shunk, D. y Callarman, T., 2006. Value chains versus supply chains. BP trends, March Edition.

Habib, M., 2011. An Exploratory Analysis of Educational Management for the Universities. International Journal of Engineering Business Management, 3 (3), 16-24. 
Habib, M., 2010. Supply chain management: theory and its future perspectives. International Journal of Business, Management and Social Sciences, 1 (1), 79-87.

Habib, M. y Jungthirapanich, C., 2010. International Supply Chain Management: Integrated Educational Supply Chain Management (IESCM) Model for the Universities. En: Gupta, S.L. International Retailing: Text and Readings. Excel Books, 1-18.

Lambert, D.M., Cooper, M.C. y Pagh, J.D., 1998. Supply Chain Management: Implementation Issues and Research Opportunities. The International Journal of Logistics Management, 9 (2), 1-19.

Lau, A.K.W., 2007. Educational supply chain management: a case study. Emerald Group Publishing Limited, ISSN 1074-8121, 15 (1), 15-27.

Machuca, J. A. D., Ortega Jimenez C. H., Garrido P., Perez J. L., 2011. Do technology and production strategy links enhance operational performance? Empirical research in the auto supplier sector. International Journal of Production Economics, 133(2), 541-550.

Ortega, C.H., 2011. Demanda y oferta de educación superior II: Operativización del modelo del sistema integrado de valor y de suministro de Educación Superior (SIVSES), documento de trabajo, Instituto de Investigaciones Económicas y Sociales (IIES), UNAH, Tegucigalpa, 2011.

Ortega, C.H., y Eguía, I., 2011. Demanda y oferta de educación superior: Integración total de la cadena de valor y las cadenas de suministro. Economía y Administración (E\&A), 2 (1), 21-50.

Ortega, C. H., Garrido-Vega, P., Machuca, J. A. D., 2012. Analysis of interaction fit between manufacturing strategy and technology management and its impact on performance. International Journal of Operations \& Production Management, 32(8), 958-981.

Ortega Jimenez, C. H., Garrido, P., Perez, J., Garcia, S., 2011. Production strategy-technology relationship among auto suppliers. International Journal of Production Economics, 133(2), 508-517. 
Pathak, V. y Pathak, K., 2010. Reconfiguring the higher education value chain. Management in Education, 24(4), 166-71.

Porter, M. E., 1985. Competitive Advantage_Creating and Sustaining Superior Performance, Free Press, New York.

Ramsay, J., 2005. The real meaning of value in trading relationships. International Journal of Operations \& Production Management, 25, 549-65.

\section{(Footnotes)}

1 Puede ser otra unidad académica interna.

2 Maestros de ES como parte del servicio de apoyo primario y/o de EM como parte del servicio de apoyo primario a la cadena de valor de EM que permita la mejora de sus graduados como estudiantes de ES.

3 Ver proceso de cadena de valor y relaciones (Ortega y Eguía, 2011).

4 El valor añadido permite evaluar al ofertante sobre la calidad, volumen y nivel de investigaciones derivadas durante el suministro de insumos a lo largo de su procesamiento académico. Ello incluye evaluar la calidad de los proyectos de Tesis en todos los niveles. 